\title{
Exploring the Reading Strategies used by Form 4 English Language Learners
}

Farah Hani Kasman, Parilah Mohd. Shah

To Link this Article: http://dx.doi.org/10.6007/IJARBSS/v11-i11/11518

DOI:10.6007/IJARBSS/v11-i11/11518

Received: 08 September 2021, Revised: 04 October 2021, Accepted: 21 October 2021

Published Online: 02 November 2021

In-Text Citation: (Kasman \& Shah, 2021)

To Cite this Article: Kasman, F. H., \& Shah, P. M. (2021). Exploring the Reading Strategies used by Form 4 English Language Learners. International Journal of Academic Research in Business and Social Sciences, 111(11), 116-138.

\section{Copyright: (c) 2021 The Author(s)}

Published by Human Resource Management Academic Research Society (www.hrmars.com)

This article is published under the Creative Commons Attribution (CC BY 4.0) license. Anyone may reproduce, distribute, translate and create derivative works of this article (for both commercial and non-commercial purposes), subject to full attribution to the original publication and authors. The full terms of this license may be seen at: http://creativecommons.org/licences/by/4.0/legalcode

\section{Vol. 11, No. 11, 2021, Pg. 116 - 138}

Full Terms \& Conditions of access and use can be found at http://hrmars.com/index.php/pages/detail/publication-ethics 


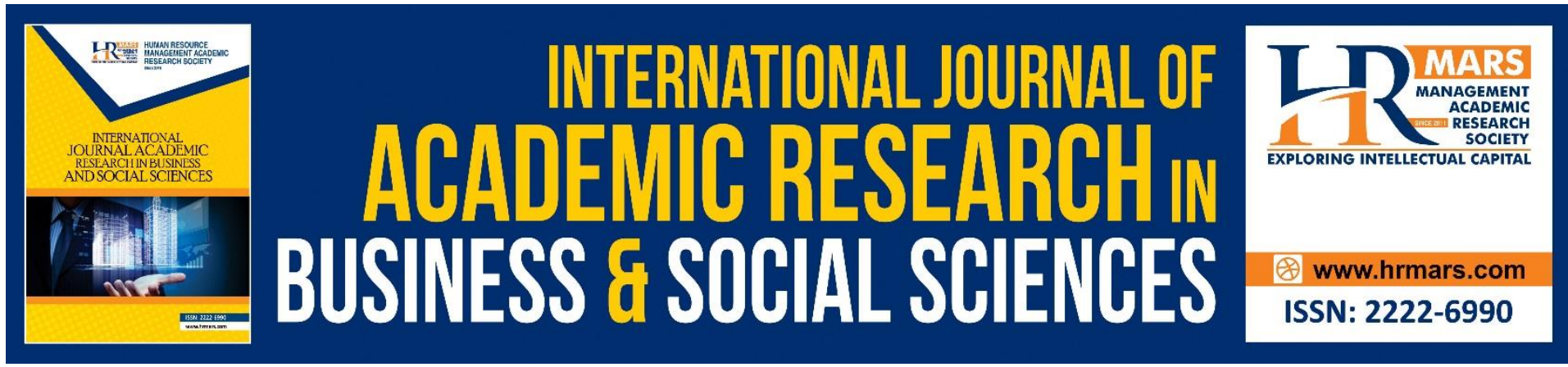

\title{
Exploring the Reading Strategies used by Form 4 English Language Learners
}

\author{
Farah Hani Kasman, Parilah Mohd. Shah \\ Faculty of Education, Universiti Kebangsaan Malaysia, Selangor,MALAYSIA \\ Email: farahhani77@gmail.com,drparila@gmail.com
}

\begin{abstract}
Reading skills have become one of the common concerns that have been discussed among the researcher until today. However, learners still encounter numerous hurdles in discerning reading texts, such as understanding the meaning of texts and the structure of sentences. These issues existed because it has been discovered that several unskilled learners could not implement an effective reading strategy that affects the learner's comprehension of the materials. Hence, this study was intended to determine the reading strategies practiced by Form 4 English languages and identifying whether there is a significant difference between male and female learners regarding the reading strategy used. The participants of this study have involved 26 learners of Form 4 English language learners of a national secondary school in Hulu Langat, Selangor. This study has used a survey design approach with questionnaires utilized in obtaining the data. Then, the questionnaire has been analyzed using descriptive analysis. The study's findings have revealed that metacognitive strategies were the most preferred reading strategies throughout the reading process. Meanwhile, there was no significant difference detected between male and female learners regarding the reading strategy used. The discovery and implications of this study enable to assist ESL teachers and educators in applying proper reading skills strategies during English language teaching in a classroom.
\end{abstract}

Keywords: Secondary School, Reading Skill, Reading Stages, Metacognitive, Cognitive

\section{Introduction}

\section{Research Background}

The English language has evolved to become the primary language used in various educational settings. It's also a language that's been used as the primary mode of communication throughout the planet. The English language has also been used in various disciplines relating to new technologies, scientific expeditions, and advanced research investigations (Suran 2016). The acquisition of the language itself may provide several benefits to learners in the future. It plays a critical part in a learner's development, allowing them to acquire superior information and skills. For example, the knowledge and abilities gained enable individuals to take advantage of worldwide prospects, thereby propelling our country's commercial development. 
Furthermore, according to Al Roomy (2019), learning English enable learners to gain additional skills and ways to deal with problems when continuing their studies at a higher level of education. However, to learn the language, learners must master English's four primary language abilities: reading, writing, speaking, and listening. On the other hand, reading skills were the most important skill that learners needed to acquire first, followed by the other three language skills.

Reading abilities were one of the most common concerns that researchers disputed until today. Other scholars have argued that reading ability is one of the essential abilities that learners must acquire, particularly for first and second-language learners. Reading is a complex activity that involved a combination of memory and interpretation generation in extracting elements from a text. According to Alfassi, as cited in Zare \& Othman (2013), it is also regarded as a talent that necessitated a series of actions that can aid learners in gaining more understanding about a text as they read it. Gog (2019) also stated that activities like grasping and remembering ideas, concentrating on specific details, and synthesizing information aid learners in comprehending the text's actual interpretation, allowing them to go beyond the surface meaning and understand the reading materials on their own. Sookchotirat (2005) stated that reading is one of the most fundamental abilities that learners should master because it can provide them with various benefits during the language learning process. The researcher went on to say that being a good reader gives learners more knowledge because they can read numerous reading texts. It also allows learners to expand their grasp of the literature by exploring new concepts and studying more extended portions of the text. Ahmed (2018) also stated that improving one's reading ability can help learners comprehend a text. This action allows them to connect the text provided with their past knowledge, making the process more enjoyable and enjoyable. Sultana (2014) went on to say that both first and second language learners need to be able to read English books to get information and enhance their reading skills.

However, to be strong readers, learners must choose the best technique for improving their reading abilities. Learners must identify the correct reading technique rather than relying solely on specific skills. Each learner may have more than one approach for understanding during the reading process that works effectively for them. According to Afflerbach et al. (2008), reading the text repeatedly without utilizing specific tactics during the reading process does not automatically result in text comprehension. The researcher went on to say that learners will be able to consistently comprehend the text if they can use the right and appropriate strategy to learning the words and decoding the meaning of the text. As a result, learners must decide on proper reading techniques throughout the reading process, including before, during, and after reading. When the appropriate strategy is used throughout the reading process, learners are expected to be more vigilant in understanding its relevance rather than only getting the meaning from a specific text. According to Al- Roomy (2019), depending on methods and comprehending their value might help learners gradually improve their reading comprehension of the text. Learners will pay more attention to the reading strategies and see again in reading comprehension, allowing them to succeed academically.

\section{The Rationale of the Research}

This study focused on conducting its purpose which is identifying the reading methods utilized by Form 4 English language learners throughout the reading process. This study was conducted as each English language learner may employ different reading tactics before, during, and after reading, depending on their ability to comprehend the material. This 
research may assist teachers to identify their learners' preferred reading strategies before, during, and after reading. Teachers could design and used the appropriate reading strategies for individual learners to help them understand the text's content. Understanding the differences between Malaysian male and female ESL Form 4 learners in reading strategies is very critical. The teacher can used various tactics based on gender in class to help both genders focus and read. Furthermore, this study allowed teachers to identify how the learners' level of understanding influences their reading strategies before, during, and after reading. Teachers could support learners enhance their knowledge by applying various reading strategies before, during, and after reading. Finally, this study encouraged learners to learn more about pre, during, and post-reading approaches. Most Malaysian ESL learners are unaware of reading strategies since they are not exposed to them in school. While reading, learners may figure out their reading approach. As a result, this study helped learners recognized their reading methods, which improved their comprehension of the text throughout their reading session.

\section{Problem Statement}

Reading is more than merely learning the contents of a text. It is a skill that requires a diverse set of abilities, as well as a comprehensive cognitive and metacognitive process that encompasses something more than reading the whole thing. Moreover, the implementation of proper strategies may aid learners to intensify their comprehension even better. Pani (2004) stated that English language learners may grow to be good readers if they can employ the methods competently and efficiently during the reading stages compared to poor readers. Besides, the ability to master the skill of reading by consciously utilizing various reading strategies usually facilitates language learners to gain more reliable knowledge of the text. Furthermore, it also allows learners to actively engage in understanding the content of written materials and achieve the desired reading comprehension goal. Jeevaratnam (2020) stated that applying various strategies during the reading stages is crucial for learners as it requires our mental to operate actively and engaged readers to explore a particular text successfully to make sense of what they read. Various reading strategies have been reviewed and even highlighted their advantages in enhancing learners reading comprehension. ESL readers may have used some ways in their reading process, such as conceptualizing, rereading, using a dictionary, and more appropriate methods, such as investigating implications and writing a summary in comprehending the context of the reading material (Rastakhiz \& Safari 2014). Yet, learners still facing numerous hurdles and the incapability to determine the appropriate reading strategy that affects the learner's understanding of the texts.

This difficulty still exists among most learners nowadays. It is happening among learners who are in high school and reading becomes the primary skill that needs to obtain by them in understanding the meaning of knowledge. In Malaysia, Form four learners are in the qualifying stage for their main examination, the Malaysian Certificate of Education examination, conversely as Sijil Pelajaran Malaysia (SPM). During this phase, the learners seem to encounter some difficulty still when it comes to reading comprehension. Understanding through reading is crucial as it could assist learners in acquiring an excellent result, especially in the test related to read for comprehension. But, few learners are struggling to enhance their awareness as they encounter some problems during the stages in reading. Applying the right strategies during the reading stages is crucial, however, it depends on the learner's proficiency and abilities to implement the methods efficiently. 
The inability to select the right approach during reading may cause learners to become discouraged and uninterested in reading. According to Grigoryan (2020), supplying learners with adequate knowledge of effective reading methods might boost their motivation and engagement in reaching excellent reading comprehension of the material. It was emphasized by Carell, Pharis, \& Liberto (1989); Mokhtari \& Sheorey (2002) indicated that learners could deal with this issue by selecting the appropriate options to strengthen their reading comprehension. Therefore, not only by reading to understand learners need to apply the proper technique during each reading stage is essential to facilitate learners to thrive in language improvement. Zhang and Seepho (2013) affirmed that the ability of language learners to apply the strategies accordingly and frequently might be helpful in overcoming their difficulties in language proficiency. In addition, it also may allow language learners to achieve their goal of enhancing their reading comprehension and perform better in academics. Hence, this study has attempted to answer two guiding questions concerning the strategies during pre, while, and post-reading stages by Form 4 English language learners.

\section{Research Questions}

This research has strived to answer the two guiding questions regarding the reading strategies used by the English language learners which are:

1. What are the reading strategies used by Form 4 English language learners?

2. Is there a significant difference between male and female learners concerning the reading strategy used?

\section{Literature Review Introduction}

The literature and theoretical studies that are required for this research have been discussed in this chapter. In any research project, it is vital to employ a literature review as a source. Importantly, it enables every researcher to comprehend everything that needs to be included in their research paper. This, in turn, enables every researcher to comprehend everything that needs to be included in the study paper. According to Young (2017), most researchers argued that researchers could not undertake an appropriate study without a large body of literature on inter. The researcher has investigated some of the literature with the same information related to the field of this study. The literature has branched into numerous sections, including reading skills, pre-reading while reading along with post-reading stages, reading strategy, and the study's theoretical framework.

\section{Reading Skill}

Reading is frequently viewed as a method for learners to absorb the meaning of the material offered in a written text. According to Dean (2013), reading is not merely a talent easily acquired through reading. It is a talent that needs a learner to study and comprehend the written text's fundamental objective properly. Furthermore, after understanding the text's elements, learners can use this skill to create a new definition. Ahmed (2020) underlined that learning to read allows learners to increase their language and vocabulary understanding through a process that involves the learner looking for crucial hints using their prior knowledge.

Furthermore, it is beneficial for learners to distinguish between various written texts by linking the information gained from the text to the information they already know to obtain 
possible meaning (Dildora 2020). Furthermore, language learners must possess this talent because it plays an integral part in their academic advancement. Again, Sultana (2014) underlined that learners must gain reading skills because this talent can assure a learner's success in education during the language learning process and provide tremendous opportunities for learners in the future. According to Burt, Peyton, and Adam (2003), this skill can help learners improve their vocabulary, stimulate new ways of thinking, gain confidence in writing, and master a broader range of new skills.

\section{Pre-Reading, While Reading and Post-Reading Stages}

Reading comprehension cannot be achieved solely by reading the text without experiencing the proper stages in reading. Knowing the significance of reading stages in the beginning stages of learning to read may aid learners to intensify their reading skills and overcome their difficulties in understanding the main context of the text. Besides, learners need to be aware of most researchers' reading stages in previous studies. Grigoryan (2020) has affirmed that English language learners must develop their reading skills by undergoing these three stages, pre-reading, while- reading, and post-reading. The researcher added that learners reading proficiency could be improved when they can recognize the significance of each of the stages in reading. These stages intended to aid the learners in comprehending the text even before the reading process begins to strengthen their understanding during reading and review the meaning by incorporating their core knowledge during the process. Pre- reading is the first stage in the reading process that enables learners to make predictions about the topic and grasp the context of the written text. It is a stage that permits learners to brainstorm some innovative keywords related to the text given. Yan (2020) explained that these predictions were constructed to activate the learner's schemata and stimulate the learner to figure out whatever the text is all about. For instance, introducing the learners to the content with some assistance details like the title, pictures, graphs, and others may prompt learners to point out a few ideas that could be shared with others before the reading process has begun. Nazurty (2019) also stated that this process stimulates learners to be engaged in giving opinions about the text with the clues that have been provided and applying their existing knowledge may generate this process to become intriguing in attracting their interest to read the text.

Next, the second reading stage is called a while-reading stage. The while- reading stage is the stage that encourages the learners to build their understanding of the text and let them be engaged in the reading process by applying some suitable and appropriate strategies. It is also a process that helps the learners understand the text's purpose and structure, (Pranata 2019). During this stage, learners will begin to discover the main idea or the text's primary purpose by recognizing the details, knowing the text structure, identifying the supporting particulars, and others. Moreover, this stage will help the learners be more focused on clarifying their understanding by connecting the opinions and ideas related to the text. This process allows the learners to communicate with their existing knowledge, strengthening their understanding of the text (Amin 2019). Strategies such as scanning and skimming are used during this stage to check comprehension, confirm predictions, and answer uncertain questions in getting a complete understanding of the text (Ozek \& Civilek, 2006).

Finally, is the post-reading stage. The post-reading phase is the final in the reading process, and it is also a vital stage as the two previous stages mentioned before. The post-reading stage is a stage known as the summarization process that requires the learner to summarize the whole text by creating a condensed version containing the main ideas and essential 
supporting points (Adler 2001). This process was done after the learners have read and digest the whole meaning of the text. Furthermore, this stage allows the learners to determine the core ideas of the text by eliminating the irrelevant points and unnecessary details that could be problematic for learners to comprehend the main objectives of the text. Other than that, making a conclusion and discussing with other learners could be done during this stage. It will allow the learners to validate their understanding by making some conclusions, inferences and reflecting upon what has learned during the process (Nordin et al. 2012).

\section{Reading Strategy}

Reading strategy is also defined as an attempt of the reader by applying some appropriate approach to understand words and comprehend the meaning presented in the text (Afflerbach, Pearson \& Paris, 2008). These approaches were designed to assist learners choose the best approach for planning and deciding the purposes of understanding the text, assessing their comprehension while reading, and reflecting their viewing experience (Wolfe et al., 1998; Meniado, 1998). However, determining the right strategy might be challenging as it requires a lot of practice and time-consuming. Even so, discovering the appropriate reading strategy that suits the level of the learner's intelligence and understanding may affect the learner's reading comprehension. It is also emphasized that applying different reading strategies may enhance learners' reading comprehension (Chomphuchart, 2006; HoFang, 2008, Nordin et al., 2013).

Moreover, determining the appropriate strategy helped learners to be more confident and skillful which enables them to meet the requirements of the reading task. Reading strategies or also known as learning strategies in language learning have been divided into several categories which are cognitive, metacognitive, memory, affective, compensation, and social strategies, (Oxford 1990). Cognitive, memory and compensation strategy are classified as the primary strategy in reading strategies. These strategies are mainly involved in using a language known as direct strategies (Lee, 2010). A cognitive strategy concentrated on understanding the language by summarizing, making predictions, analyzing, reasoning, and obtaining context clues by note-taking (Zare, 2012). Techniques that required a learner to recall information, forming mental linkages by using the images and sounds, and retrieving data are all part of memory strategies. The last division of direct strategies is the compensation strategy. Compensation strategy guide learners to be skilled at constructing inferences and guessing while reading, which permits the learner to overcome the gaps in obtaining the reading skill.

Furthermore, the other category of reading strategy is called indirect strategies. Metacognitive, affective, and social strategies are categorized as indirect strategies that facilitate language learning but do not involve direct involvement (Lee, 2012). Metacognitive strategy exposed learners to plan, arrange their learning and way of reading, and evaluate their reading comprehension. Affective strategy is used to assist learners in enhancing their confidence, overcoming anxiety, and improve self- encourage while learning something. Finally, the social strategy focused on the interaction between an individual with others that requires them to work in groups together, asking and answering some questions along with empathizing with others.

Apart from all the strategies mentioned before, reading strategies such as metacognitive and cognitive strategies are the most utilized strategy among learners during the reading process. Kasemsap and Lee (2014) stated that metacognitive and cognitive strategies could be 
regarded as primary strategies to enhance learners' reading comprehension. Cognitive reading skills involve the capability to obtain knowledge, understanding of the context, comprehend a particular meaning by referring to the dictionaries, recalling and retaining the information (O'Malley \& Chamot, 1990). The in-depth, mental strategy mostly will involve the use of prior knowledge, which can be helpful for the learner to relate a particular text with their existing knowledge. Besides that, in the beginning stages of reading, cognitive strategy was most likely the most important step. It will activate the learner's mental processes in comprehending the written materials, retrieving information from memory, then organizing the data into main goals and sub-goals to achieve the purpose of the reading process (Sheorey \& Mokhtari, 2001).

On the other hand, metacognitive approach is the global reading strategy that emphasized an individual's conscious ability to manage the way they read, obtain information from their reading, and engage with that knowledge throughout accomplishing specified objectives (Flavell, 1976). It is also viewed as the higher- order skill in the reading process that involves fulfilling the particular purposes for reading through planning, monitoring, and evaluating the information obtained from the written text, (O'Malley \& Chamot, 1990). The learners will be able to take over control of their reading process in acquiring the knowledge from the written text. This strategy permits learners to consciously aware of their ability in utilizing skills such as modifying their reading pace according to the difficulty of the text, discovering the most crucial information from the text, exploiting contextual hints, and so on (Meniado, 2016). Thus, these reading strategies during the reading process has shown their significance in enhancing the learners reading comprehension to a higher level. Reading strategies may become the best assistance for learners in achieving the real purpose of reading which is to empower learners with more knowledge through reading various academic English languages written text.

\section{Theoretical Framework}

Reading is vital to the progress of reading comprehension. The assistance of using various strategies during the reading process may assist English language learners in being more understanding in grasping the essence and content of a particular text. Assuring learners to employ proper strategies during the reading process will empower learners to obtain a broad spectrum of knowledge and better comprehension of the written text depends on the learners' level of competencies. In reading comprehension, various researchers have discussed implementing cognitive and metacognitive models throughout the reading process, which are pre-reading, while reading and post-reading. The implementation of these two models in reading will enable learners to achieve their goals in reading. The cognitive model is also known as a theory that uses the top-down approach in reading comprehension. The top-down approach referred to the active organization, which will allow learners to obtain an understanding through relating the information with their past experiences. Besides, it is a theory that presents how the learner acquired, processed, and retrieved the knowledge through employing some skills, strategies and reflecting on their experiences related to the reading text. In addition, learners can perceive the text by combining their prior knowledge with the information in a text. In this process, the learner's former knowledge and knowledge construction may operate efficiently with the help of reading strategies (Zhao \& Zhu, 2012). It also indicates the interaction process between the text and the learner's prior knowledge using some proper methods in forming a new meaning of the text. Moreover, this model facilitated learners to use cognitive methods such as jotting down some vital information, 
reviewing, and employing main ideas to perceive a written text during the reading process using past knowledge.

On the contrary, a metacognitive model is known as a model that referred to the actions and interactions among four essential aspects, namely metacognitive knowledge, metacognitive experience, goals, and approaches in the reading process is being used to monitor a wide range of intellectual operations, (Flavell, 1987). Metacognitive knowledge pertained to the understanding or perceptions regarding variables such as people, tasks, and strategies. He has stated that metacognitive learning is not fundamentally different from other forms of long-term memory knowledge. The sections of this stored knowledge are called metacognitive experiences. These mental experiences have entered consciousness. That is, "any conscious cognitive or affective experiences that attend and belong to any intellectual effort," are known as metacognitive experiences. Metacognitive experiences are indeed possible to fall in conditions that possess a wide range of attentiveness or "metacognitive knowledge." Metacognitive information was sometimes earned, rejected, or transformed through metacognitive experiences. The accomplishment of the specific outcomes reflects the actual goals of a cognitive effort.

Finally, as the name implies, actions or strategies are specific methods and procedures that can help you achieve your objectives. Dirkes (2010) stated that it is a model with the implementation of metacognitive skills that includes relating new information to former knowledge, choosing thinking strategies independently, planning, monitoring, and evaluating thinking processes during the stages in reading. Many researchers have agreed that implementing these two models has helped learners construct and understand the meaning of the reading text. Livingston (2017) expressed that cognitive and metacognitive strategies are inextricably linked and reliant on enhancing reading comprehension. Gilakjani and Ahmadi (2011) also stated that utilizing some appropriate strategies during the reading process might assist the learners in attaining the information in their memory for a long time. Several studies have been conducted. However, most of the prior studies focused on using metacognitive and cognitive strategies in reading among learners in a higher level of education. Sheorey \& Mokhtari (2001) stated that these research studies were restricted to comparing learners with high and low proficiency levels and those in secondary or preuniversity education internationally. There was a study administered by Phakiti (2003) investigated the significance of implementing cognitive and metacognitive reading strategies in an EFL reading comprehension test among Thai English Foreign Learners (EFL). Moreover, the researcher also attempted to discover the correlation linking learners' reading comprehension results and the implementation of the reading strategies during the process. It also looked at how the learners from different categories such as extremely successful, somewhat successful, and unsuccessful learners operate the reading strategies differently. The study's findings revealed that cognitive and metacognitive approaches undoubtedly affected learners' performance on a reading comprehension test. It was also discovered that highly successful learners employ significantly more metacognitive strategies than moderately successful learners and that moderately successful learners use significantly more metacognitive strategies than the unsuccessful learner.

Correspondingly, a similar study has been conducted by Naeni and Rezaei (2015), examined the relationship between the implementation of cognitive and metacognitive reading strategy with the reading comprehension in diverse conditions. They investigated the varying constructs of Iranian English learners' application of various skills while undertaking a reading 
proficiency test and the correlations between the learners' reading skills achievement and the cognitive and metacognitive learning strategies practiced by the learners. There was a considerable correlation between the learners' reading competency performances and their understanding while taking the test. It also indicated a substantial difference between successful and unsuccessful readers. The results show that more strategies have been employed by prosperous readers as they are knowledgeable of the importance compared to less unsuccessful readers who are not competent in utilizing the strategies efficiently.

Another study has been administered by González (2020), which concentrated on the applications of cognitive and metacognitive strategies in assisting English Foreign Learners $(E F L)$ to approach reading passages found in tests. This research also involved adult learners with diverse qualifications and has experienced Formal education through their high school years. The central focus of this research is to distinguish the cognitive and metacognitive strategies uses by the EFL during the reading process throughout the reading comprehension examination. After the analysis has been carried, the results have indicated that a high level of the EFL has preferred to use cognitive strategies compared to metacognitive strategies during the reading comprehension test. This decision is because, through mental processes, EFL tends to practice higher prediction, analyzing and visualizing methods. Through the prediction method, they could assume and predicts the meaning of certain words to comprehend the essence of the text. As for analyzing, they tend to explore the text at the beginning of the reading process by studying the pictures shown in the text to obtain some crucial clues about the text and highlighting some essential words by jotting down the vital points that could assist them in understanding the context of the text. Lastly, the visualizing methods permit them to envision some connections between the words that may enable them to get the actual information portrayed from the text.

However, not all studies in the same field yield the same results. Sari (2016) examined cognitive and metacognitive strategies and the reading comprehension of Indonesian EFL preservice teachers. The goal of this study was to investigate the reading methods used by Indonesian EFL pre-service instructors. It also aimed to discover the link between reading methods and reading comprehension. There was a reading exam and a questionnaire on cognitive and metacognitive reading techniques. Less Successful Readers (LSR), Highly Successful Readers (HSR), and Moderately Successful Readers (MSR) were the three groups formed based on reading test results (MSR). Highly Successful Readers (HSR) favored cognitive reading techniques, whereas Moderately Successful Readers (MSR) preferred metacognitive reading strategies. There was no significant difference in reading comprehension performance amongst Indonesian EFL pre-service instructors who used metacognitive and cognitive reading strategies.

Furthermore, the researcher noted that technical issues, such as test inaccuracy and process and a person's language skills, could alter the study outcomes. Moreover, few researchers looked at the most favored metacognitive and cognitive techniques among learners. Commander, Ashtong, and Zhao (2016) studied undergraduate learners' reading strategy choices in the US and China. The study found that US and Chinese learners had similar overall strategy choices. Both groups used cognitive tactics the most. However, metacognitive tactics were the second most popular type, while support methods were the least popular. According to Nazurty et al (2019), Indonesian Language Education Learner Teachers prefer reading tactics. The study found that Indonesian language learners' teachers used more cognitive than metacognitive methods when reading. According to the researchers, language learner teachers prefer to employ an approach that allows them to apply prior knowledge to help 
them comprehend the text when reading. Maarof and Maasum (2012) examined Malaysian EFL undergraduates' reading techniques. According to the statistics, cognitive strategies are the most popular among learners. But metacognitive methods were the second most popular and ranked high in utilisation. In addition, Goh (2019) found that Malaysian ESL learners are more likely to apply cognitive methods in the reading process. According to the study, learners preferred to create predictions based on preliminary information during the reading process. A small number of studies have investigated how secondary school learners employed reading methods before, during, and after reading. Hence, this study was conducted to investigate the reading approaches used by Form 4 English language learners during the reading stages and to see if there is a substantial difference between male and female learners concerning the strategies used.

\section{Methodology}

\section{Introduction}

The approach employed in the study was discussed in this chapter. It started with the research design, then moved on to the study site, study subjects, instruments, and data collection techniques before ending with the survey's data analysis.

This study was conducted by using the survey research design. The researcher has used the survey research design to focus on the objective measurements. A survey research design is a type of research that examined the aspect of a specific community by collecting the data that describes beliefs, opinions, or characteristics of the community analyzed using a mathematically based method (Creswell, 2012). This research design enables the researcher in identifying the respondent's viewpoint and answers on determining the most used strategies during the pre and post-reading stages that improved the learner's reading comprehension.

The study was conducted in one of the central national secondary schools in Hulu Langat, Selangor. The school was situated in a village area called Kampung Sungai Gahal, Hulu Langat, Selangor. It is a daily secondary national school that operated two-session schooling time, a morning and evening session for learners and even teachers. It is also a rural school located in a diverse community housing area mainly filled by Malay community followed by several Chinese and only a few Indian societies. The school was first built in the early year of 1965 and started to develop more with new buildings that include constructing new dormitory blocks for Form six learners, a small praying building, and even new classroom buildings in the recent year. Furthermore, this school was occupied almost 2000 learners from 1 until Form 6 , consisting of more than five classes for each level. As for the study subjects, the researcher has selected 26 learners of Form 4 learners, consisting of 15 girls and 11 boys. The subjects were among Form four learners with high and low proficiency in the English language reading comprehension. Besides that, the researcher decided to choose Form four learners because they are unbound with the leading national public examination, which is called Sijil Pelajaran Malaysia or SPM. The selection of these subjects allowed the researcher to approach the subjects effortlessly. However, due to the spread of Covid-19, the researcher has considered other alternatives to collect the data for the research.

Furthermore, the researcher has used a set of questionnaires adapted from previous studies as the instruments of the studies. Survey of Reading Strategies (SORS) consisted of statements about reading strategies such as metacognitive $(\mathrm{MC})$ and cognitive (C) strategies (Baker \& Boonkit, 2004; Oxford, 2003; Sheorey \& Mokhtari, 2001). According to Mokhtari and Sheorey 
(2002), the purpose of SORS is to "measure the occurrence and variety of reading strategies that younger and adult ESL learners employed while reading educational materials in English". The researcher has converted the questionnaire into a Google Form. The set of the questionnaire consisted of 5 parts: Part A for demographic information, Part B on the strategy used during pre-reading, Part $C$ on the method used while reading, and Part $D$ on the technique used during post-reading. A survey that applied a 4-point Likert scale from Strongly Agree, Agree, Disagree and Strongly Disagree.

A total of 22 items related to the reading strategies have been included in the questionnaire. The survey has addressed five items regarding pre-reading activities, fourteen items were for while-reading activities, and three were for post-reading activities. The researcher has implemented a well-organized pattern to make the respondents comfortable while answering the questionnaire. The researcher also attempted to find out the respondents' feedback towards using metacognitive and cognitive strategy during pre, while and post-reading stages with English language reading materials through the questionnaire. The researcher has approached the school's selected English language teachers that taught Form four learners and asked permission to conduct the reading activity during their online classes. During the activity, the teacher has conducted a reading activity that required learners to apply their reading strategy during the pre-reading, while reading and post-reading stages. A text from the Form four English textbook was used as the material for the study. Then, the online survey was disseminated to the four English language learners after the reading activity ended. The learners were given only 15 to 20 minutes to answer the survey. The primary goal of the strategy survey was to determine the types and frequency of reading strategies used by participants when reading any English educational text. During the process, each of the subjects must choose only one choice for each of the statements.

Then, the researcher analyzed all the data obtained during the data collection to identify the answers to the study's research questions. The researcher analyzed the findings of the data by using descriptive statistics. Descriptive statistics will be used to analyze the demographic background and questionnaire data, which will present the most and least preferred strategies used during the pre, while and post- reading stages among the Form four English language learners. The frequencies of the reading strategies were presented in the form of several tables. Besides that, the significant difference between male and female learners concerning the reading strategy used was analyzed using the SPSS (v. 22) software packages. The data obtained has been inserted into the SPSS software and run an independent t-test. The T-test has presented the differences in using metacognitive and cognitive reading strategies between female and male Form 4 English language learners.

\section{Findings}

\section{Introduction}

This chapter summarized the study's findings. The study results from the survey response options are thoroughly examined to answer research questions 1 and 2 . The collected data were analyzed using the participants' responses, which included statements regarding reading methods strategies such as metacognitive $(\mathrm{MC})$ and cognitive $(\mathrm{C})$ strategies. A total of 22 items were included about reading practices. Strongly agree, Agree, Disagree, and Strongly disagree are the only options available to the learners for each of the statements. The table for the data analysis displayed the total number of respondents $(n)$ and the percentage for each of the options chosen. 


\section{Research Question 1}

What are the reading strategies used by form 4 English language learners?

\section{Pre-reading Stage}

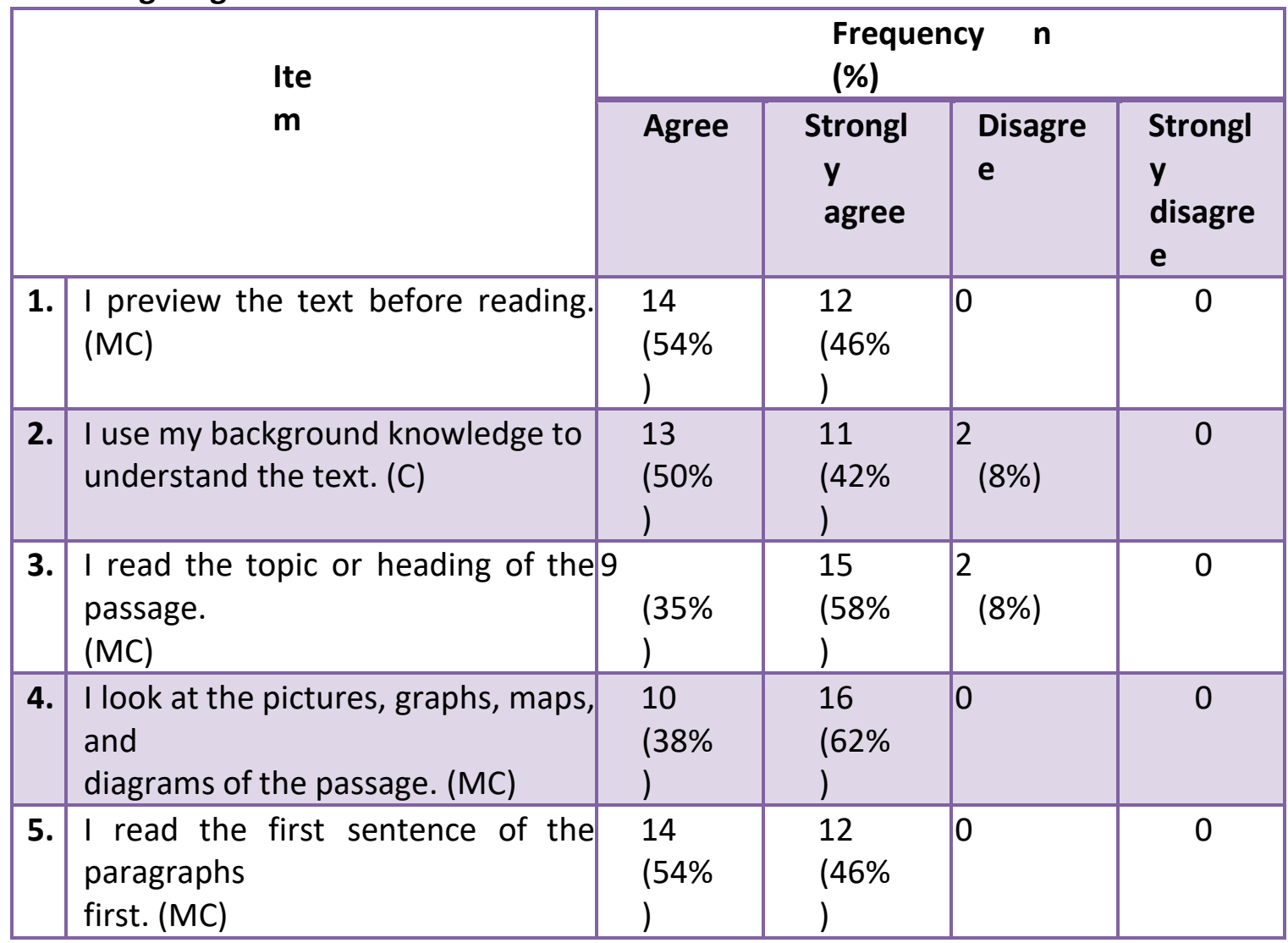

Table 1. Pre-reading Strategies

Table 1, as shown above, displayed the results gained from answering the survey regarding the strategies used during the pre-reading stage. Based on the table above, metacognitive strategies have been chosen to be the highly used strategy during the pre-reading phase among the Form four English language learners. Two metacognitive strategies obtained the highest percentage among all the methods in the pre-reading stage. The first strategy was "I preview the text before reading", which is $54 \%$ of the learners that comprises a total of 14 out of 26 learners have chosen agree, and $46 \%$ that is 12 out of 26 learners have chosen strongly agree. Another strategy with the same percentage and total of learners has selected "I read the first sentence of the paragraphs first" as the most used strategy during the prereading stage. Besides, the cognitive approach, which uses the method of "I use my background knowledge to understand the text", has obtained $50 \%$ with a sum of 13 learners who prefer agree and $42 \%$ of the learners, which is 11 out of 26 learners, have selected the strongly agree option. The other two remaining strategies were metacognitive strategies. The strategy of "I look at the pictures, graphs, maps, and diagrams of the passage" has obtained 13 out of 26 learners are $50 \%$ of them chooses to agree, and another $62 \%$ which is 16 out of 26 of the learners choose strongly agree. However, only $34 \%$ with only nine learners decide to select agree, and 58\%, 15 out of 26 learners, have chosen strongly agree for the "I read the topic or heading of the passage" reading strategies option. 


\section{While-reading Stage}

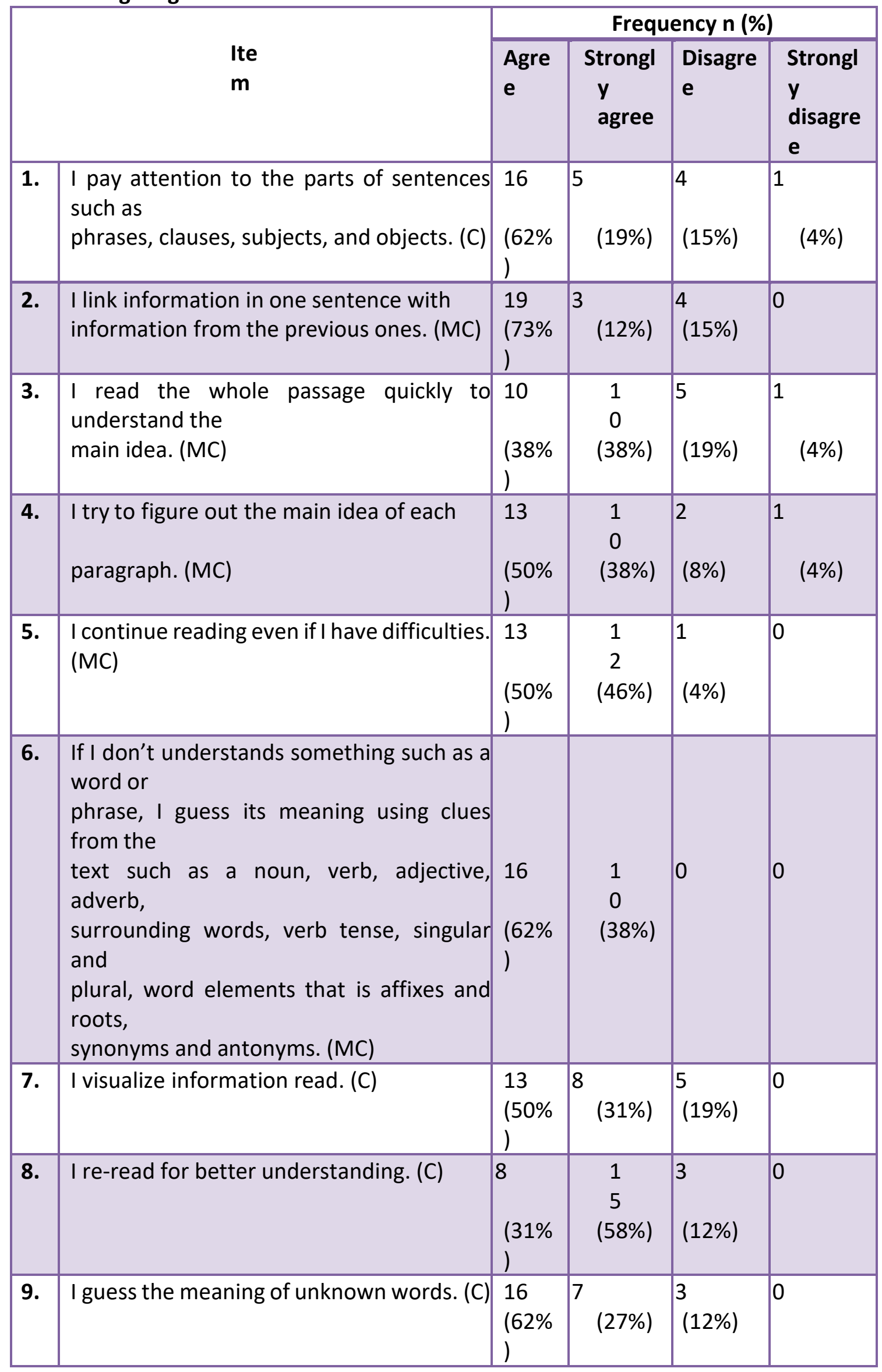




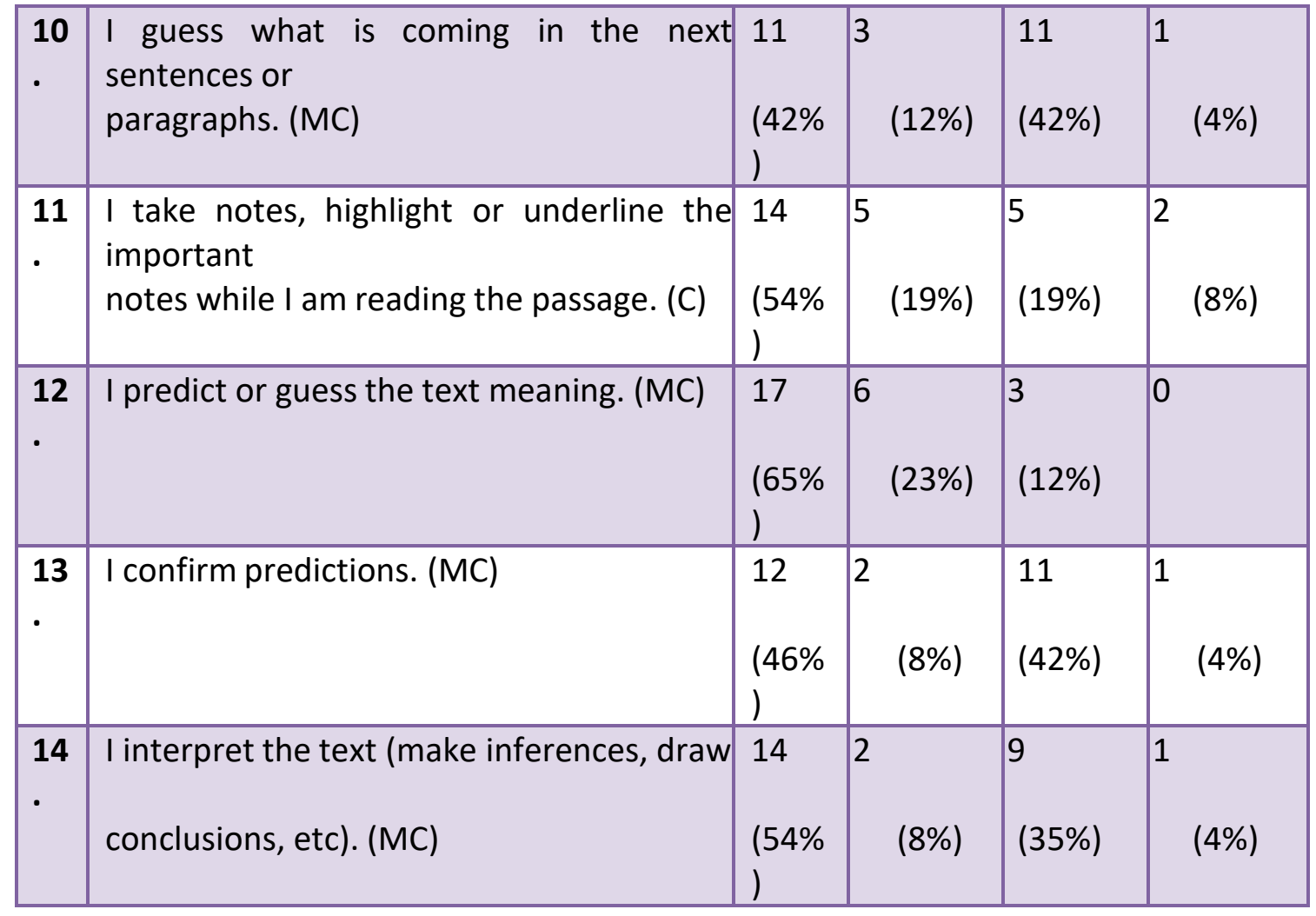

Table 2. While-reading strategies

As for the while-reading stage, the table above has revealed that the highest percentage obtained was the metacognitive strategies. The metacognitive approach is "If I don't understand something such as a word or phrase, I guess its meaning using clues from the text such as a noun, verb, adjective, adverb, surrounding words, verb tense, singular and plural, word elements that is affixes and roots, synonyms and antonyms" as the most used strategy during the while-reading stage. The method has obtained $61 \%$ that comprises 16 learners who have chosen agree, and $38 \%$ that is ten learners have preferred strongly agree. The second most used strategy was also a metacognitive strategy. The "I continue reading even if I have difficulties" strategy has obtained $50 \%$, a total of 13 learners chosen agree and another 12 learners, which is $46 \%$ of them chosen strongly agree.

Meanwhile, the highest cognitive strategies used during the while-reading stage were "I reread for better understanding" and "I guess the meaning of unknown words". Only 30\%, which is only 8 of the learners, have chosen agree, and another $57 \%$ which is 15 out of 26 learners, have chosen strongly agree for the "I guess the meaning of unknown words" method. However, for the "I re-read for better understanding" method, 61\%, 16 out of 26 learners have chosen agree, and only seven learners, $26 \%$ of them have chosen strongly agree. Besides that, the lowest metacognitive strategy during this stage would be the "I confirm predictions" method, with only $46 \%$ that comprises 12 learners have chosen agree. Only $7 \%$, which is only two learners, have chosen the strongly agree option. Lastly, the lowest cognitive strategy would be the "I take notes, highlight or underline the important notes while I am reading the passage" method that has obtained the percentage of $53 \%$ with a total of 14 learners have chosen agree and $19 \%$ which is 5 out of 26 learners have chosen strongly agree. 
Post-reading Stage

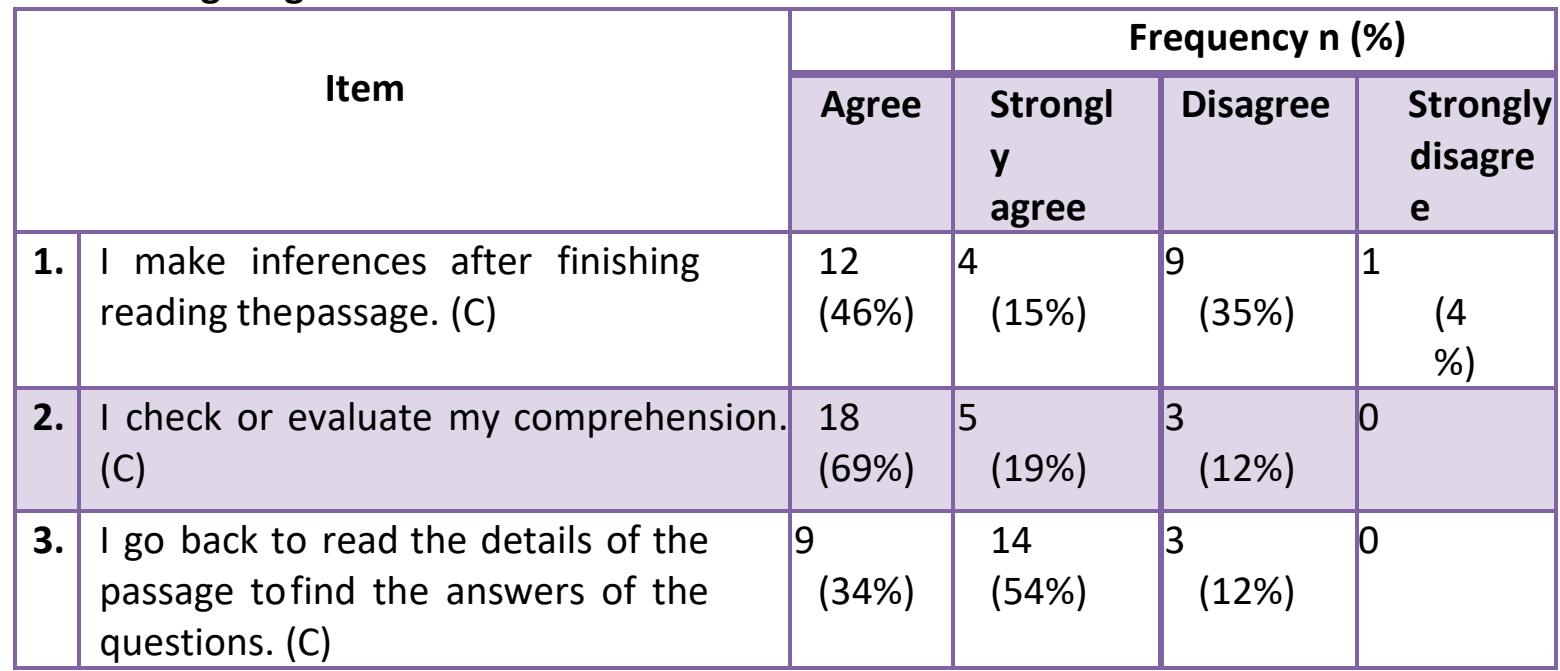

Table 3. Post-reading strategies

Table shown above presents the results for the strategies used during the post-reading stage. The results have indicated that the methods of "I check or evaluate my comprehension" and "I go back to read the details of the passage to find the answers to the questions" are the most used among Form four English language learners. A sum of 69\%, which is 18 of 26 learners, have chosen agree while another $19 \%$, only five learners have selected, strongly agree for the method of "I check or evaluate my comprehension". However, for the "I go back to read the details of the passage to find the answers of the questions" method, there are 9 out of 26 learners, which is $34 \%$ have chosen agree and $54 \%$ of the learners, which comprises 14 learners have chosen the strongly agreed option. Meanwhile, for the other cognitive strategy, the method of "I make inferences after finishing reading the passage" has obtained a total of $46 \%$, which is 12 learners have chosen agree and $15 \%$ of the learners which only four learners have chosen strongly agree.

\section{Research Question 2}

Is there a significant difference between male and female learners concerning the reading strategy used?

This section presented the findings to address research question 2. The data obtained have been computed into SPSS program to run the independent t-test. The overall mean scores were calculated to analyze whether there is a difference in reading strategy used by females and males. The results were displayed in table 4 and 5.

\section{Group Statistics}

\begin{tabular}{lll|l|r|r} 
& Gender & N & Mean & Std. Deviation & \multicolumn{1}{c}{$\begin{array}{c}\text { Std. Error } \\
\text { Mean }\end{array}$} \\
\hline Reading_strategy & female & 11 & 3.4545 & .52223 & .15746 \\
\cline { 2 - 7 } & male & 15 & 3.7333 & .45774 & .11819 \\
\hline
\end{tabular}

Table 4. Groun statistics 
INTERNATIONAL JOURNAL OF ACADEMIC RESEARCH IN BUSINESS AND SOCIAL SCIENCES

Vol. 11, No. 11, 2021, E-ISSN: 2222-6990 ๑ 2021 HRMARS

\begin{tabular}{|c|c|c|c|c|c|c|c|c|c|c|}
\hline \multicolumn{11}{|c|}{ Independent Samples Test } \\
\hline & & \multicolumn{2}{|c|}{$\begin{array}{l}\text { Levene's Test for Equality of } \\
\text { Variances }\end{array}$} & \multicolumn{7}{|c|}{ t-test for Equality of Means } \\
\hline & & \multirow[b]{2}{*}{$\mathrm{F}$} & \multirow[b]{2}{*}{ Sig. } & \multirow[b]{2}{*}{$t$} & \multirow[b]{2}{*}{ df } & \multirow[b]{2}{*}{ Sig. (2-tailed) } & \multirow{2}{*}{$\begin{array}{c}\text { Mean } \\
\text { Difference }\end{array}$} & \multirow{2}{*}{$\begin{array}{l}\text { Std. Error } \\
\text { Difference }\end{array}$} & \multicolumn{2}{|c|}{$\begin{array}{l}\text { 95\% Confidence Interval of the } \\
\text { Difference }\end{array}$} \\
\hline & & & & & & & & & Lower & Upper \\
\hline \multirow[t]{2}{*}{ Reading_strategy } & $\begin{array}{l}\text { Equal variances } \\
\text { assumed }\end{array}$ & 2.527 & .125 & -1.446 & 24 & .161 & -.27879 & .19278 & -.67667 & .11910 \\
\hline & $\begin{array}{l}\text { Equal variances not } \\
\text { assumed }\end{array}$ & & & -1.416 & 19.925 & .172 & -.27879 & 19688 & -.68957 & .13200 \\
\hline
\end{tabular}

Table 5. Independent sample T-test

The second research question aimed to identify whether there is a significant difference between the genders of Form four English language learners concerning to the reading strategies used during the reading stages. An independent-samples t-test have been used and conducted in the SPSS program to compare the reading strategy used between the females and males. The results obtained from the independent $T$ - test have indicated that there is no significant difference between male and female concerning to the reading strategy used during the reading stages. Therefore, there is no significant difference in the scores for male $(M=3.7333, S D=0.45744)$ and female $(M=3.4545, S D=0.52223)$ conditions, $t(24)=-1.446, p=$ 0.161 . These results have indicated that the reading strategy used during the pre, while and post reading stages does not influence male and female. Specifically, that these results have shown that the males and females of Form four English language learners are not significantly different when it comes to the used of reading strategy during the pre, while and post reading stages.

\section{Conclusion and Discussion}

This study has examined reading strategies, mainly cognitive and metacognitive strategies, during the reading stages like pre, while, and post-reading among the Form four English language learners. Besides that, this study has attempted to identify whether there is a significant difference between the male and female learners involving the strategy used throughout the reading stages. These results have been collected through the responses obtained from the survey as the instrument to conduct the study. The study results heightened our understanding of Form four English language learners' reading strategies during the reading stages. Based on the results gathered, the results have shown that the learners are more liked to use a metacognitive approach throughout the reading process. The findings have indicated the highest percentage obtained in the pre and while-reading stages. At the same time, the cognitive strategy remained the typical strategy used during the postreading phase. Based on the results obtained, learners preferred to use strategies to assess and investigate the text's relevant information.

Additionally, the findings of this study were consistent with the results of a previous study conducted by Rastlegar et al. (2017), which found that metacognitive methods were the most employed strategy by English language learners during the reading process. It is proven to elevate their learners' reading comprehension with its reading achievement. Metacognitive strategies such as analyzing the text before reading and identifying the words related to the topic may assist learners in acquiring a complete understanding of the context. However, several previous studies have disagreed that metacognitive strategy was the most used strategy during the reading process. According to González (2020), learners preferred to employ the cognitive method since they can predict the definitions of words based on context, mark relevant words, and even visualize information about the text. Aside from that, the findings of this study show that there is no substantial difference in reading strategies 
utilized by men and women. These findings were consistent with Abu-Snoubar (2017) findings, who discovered no significant difference in the usage of reading approaches by female and male learners during the reading phases.

Zhang (2018) also stated that gender did not significantly impact reading methods to achieve reading comprehension throughout the reading process. Due to several factors that may influence the inquiry outcomes, the results of this study may differ in some ways from those of other investigations. The study's findings may vary based on the learners' educational level and cultural differences. Furthermore, learners may have diverse reading goals and motivations when selecting a reading strategy appropriate for their level of comprehension of given reading content. Therefore, the results can conclude that Form four English language learners have preferred to use metacognitive strategies more during the reading process. The metacognitive approach allows them to activate their ability to analyze, evaluate, and plan their reading process in obtaining the information.

In a nutshell, it can be argued that learners must be mindful of and fully grasp the significance of using the correct method when reading. The effectiveness of the way was determined by the learner's ability to manage the process of reading and extracting information from a variety of reading sources. Learners may explore various kinds of reading strategies that are suitable and easy for them to understand the content of the text. Aside from that, learners should be aware of reading practices that can help them reach their reading goals and improve their academic performance. Furthermore, educators' guidance is critical in assisting learners in selecting an appropriate technique. Educators may observe their students need and try to guide them in empowering the skills which could elevate their learner's motivation while learning English. Unfortunately, only 26 Form four English language learners in secondary school are included in this study. As a result, the findings do not accurately reflect the complete Form four English language learners in the chosen school. In brief, further analysis can be conducted on this study with a larger sample size, resulting in more reliable results. Henceforth, more investigation is necessary to cover a broader range of topics so that the findings can be generalized.

To summarize, this research contributes to an exceptional realm of knowledge about secondary school students' reading techniques during the reading stages. Aside from that, this research will assuredly be beneficial to teachers and students in the future, particularly in the teaching and learning of English that stresses the use of reading skills. Educators should adopt suitable classroom pedagogical practices to complement students' needs and proficiency levels in enhancing their reading skills. The government should actively pursue practical ways and offer sufficient resources to assist teachers in improving student's reading skills to become better readers in the future.

\section{References}

Ahmed, H. M. M. (2018). Suggesting English Pre-reading and Post-reading Activities for Improving Foreign Language Learners" Reading Skill: A Case study of Learners of, Academic Year (2016-2017) Faculty of Education, University of Sinnar (Doctoral dissertation, Suggesting English Pre-reading and Post-reading Activities for Improving Foreign Language Learners" Reading Skill: A Case study of Learners of, Academic Year (2016-2017) Faculty of Education, University of Sinnar).

Ahmed, R. M. (2020). Investigating EFL Learners' Awareness of Cognitive and Metacognitive Reading Strategies of Learners in Different Disciplines. Arab World English Journal, 11(3), 294-304. 
Al Roomy, M., \& Alhawsawi, S. (2019). Understanding Reading Strategies of EFL Saudi Learners. English Language Teaching, 12(6), 33-44.

Albiladi, W. S. (2019). Effective English reading strategies: English language learners" perceptions.

Ali, A. M., \& Razali, A. B. (2019). A Review of Studies on Cognitive and Metacognitive Reading Strategies in Teaching Reading Comprehension for ESL/EFL Learners. English Language Teaching, 12(6), 94-111.

Al-Jarrah, H. (2018). Reading comprehension strategies among EFL learners in higher learning institutions. Arab World English Journal (AWEJ) Volume, 9.

Amin, M. (2019). Developing Reading Skills through Effective Reading Approaches. International Journal of Social Science and Humanities, 4(1), 35-40.

Becirovic, S., Brdarevic-Celjo, A., \& Sinanovic, J. (2017). The use of metacognitive reading strategies among learners at international Burch university: A case study. European Journal of Contemporary Education, 6(4), 645-655.

Choudhury, A. (2015). Questionnaire method of data collection: Advantages and disadvantages.

Djudin, T. (2017). Using metacognitive strategies to improve reading comprehension and solve a word problem. Journal of Education, Teaching and Learning, 2(1), 124-129.

Goh, J. X. (2019). A study on the use of different reading strategies to read English text in Malaysian ESL classroom (Doctoral dissertation, UTAR).

González, D. Z., \& Peinado, P. M. (2020). How Cognitive and Metacognitive Processes Help EFI Learners to Approach Reading Passages Found in Tests. Compiled by María Guadalupe García Assistant Editor: Ajitha. R. Manjeshwar, 119.

Grigoryan, A. (2020). Major Stages of Reading Skills Development. Armenian Journal of Special Education, 1(1), 42-51.

Hatami, M., \& Asl, H. D. (2017). The reading strategies used by EFL learners: A case of Iranian advanced English language learners. Journal of Language Teaching and Research, 8(6), 1223-1228.

Jeevaratnam, J. A., \& Stapa, M. (2020). Cognitive Reading Strategies Employed by Form Three Malaysian English as Second Language (ESL) Learners. LSP International Journal, 7(1).

Jones, T. L., Baxter, M. A. J., \& Khanduja, V. (2013). A quick guide to survey research. The Annals of The Royal College of Surgeons of England, 95(1), 5-7.

Kutluturk, S., \& Yumru, H. (2017). Cognitive and metacognitive strategy training to enhance freshmen"s reading skills. International Journal of Language and Literature, 5(1), 7-15.

Miller, G. (2017). Metacognitive awareness and reading strategy use: Investigating the intermediate level ESL learners" awareness of metacognitive reading strategies.

Nazurty, R., Priyanto, N., Anggia Pratiwi, S., \& Mukminin, A. (2019). Learning Strategies in Reading: The Case of Indonesian Language Education Learner Teachers. Universal Journal of Educational Research, 7(11), 2536-2543.

Pranata, M. S. A. (2019). The Teaching of Reading in Senior Secondary School. IJOEEL: International Journal of English Education and Linguistics, 1(2), 42-49.

Sari, M. I. (2016). Cognitive and metacognitive reading strategy use and reading comprehension perFormance of Indonesian EFL pre-service teachers. Journal of Foreign Language Teaching and Learning, 1(2), 46-61.

Suran, R. D. A., \& Yunus, M. M. (2016). A survey on learners" learning styles and strategies in a rural secondary school in Meradong district. In International Conference on 
Education (ICE2) 2018: Education and Innovation in Science in the Digital Era (pp. 767778).

Yan, N. (2020, March). A Brief Analysis of the Schema Theory on the Teaching of English Reading. In International Conference on Modern Educational Technology and Innovation and Entrepreneurship (ICMETIE 2020) (pp. 205- 207). Atlantis Press.

Zhang, X., \& Guo, L. (2020, April). Cognitive and metacognitive reading strategies training in EFL reading. In International Conference on Education, Economics, and Information Management (ICEEIM 2019) (pp. 110-114). Atlantis Press. 


\section{Appendix - Survey of Reading Strategies (sors) inventory.}

\section{Exploring the Reading Strategies used by form 4 English Language Learners}

The purpose of this survey is to collect information about the various strategies that used by form 4 English language learners when they read school-related academic materials in ENGLISH.

(e.g., reading textbooks for homework or examinations; reading journal articles, etc.).

Each statement is followed by four numbers, 1, 2, 3, and 4, and each number means the following:

1. Strongly Agree

2. Agree

3. Disagree

4. Strongly disagree

Students may choose only one choice of response for each of the questions provided. Note that there are no rights or wrong responses to any of the items on this survey. Thank you for being a part of this research project. Your cooperation is highly appreciated.

\section{PART A}

Tick $\sqrt{ }$ in the space provided. You are requested to answer all the questions given.

1. Gender

2. Race

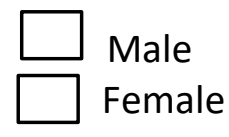

Malay

Indian

Chinese

\section{PART B (Pre - reading activity)}

Tick $\sqrt{ }$ in the space provided. You are requested to choose only one answer for each of the questions given below.

Each statement is followed by four numbers, 1, 2, 3, and 4, and each number means the following:

1. Strongly Agree

2. Agree

3. Disagree

4. Strongly disagree 
- The strategies that I prefer to choose in pre-reading activity

\begin{tabular}{|l|l|l|l|l|l|}
\hline No. & Statement & 1 & 2 & 3 & 4 \\
\hline 1. & I preview the text before reading. (MC) & & & & \\
\hline 2. & I use my background knowledge to understand the text. (C) & & & & \\
\hline 3. & I read the topic or heading of the passage. (MC) & & & & \\
\hline 4. & $\begin{array}{l}\text { I look at the pictures, graphs, maps, and diagrams of the passage. } \\
\text { (MC) }\end{array}$ & & & \\
\hline 5. & I read the first sentence of the paragraphs first. (MC) & & & & \\
\hline
\end{tabular}

\section{PART C (While - reading activity)}

Tick $\sqrt{ }$ in the space provided. You are requested to choose only one answer for each of the questions given below.

Each statement is followed by four numbers, 1, 2, 3, and 4, and each number means the following:

1. Strongly Agree

2. Agree

3. Disagree

4. Strongly disagree

- The strategies that I prefer to choose in while-reading activity

No. Statement

\begin{tabular}{l|l}
\hline 1. & I pay attention to the parts of sentences such as phrases, clauses,
\end{tabular} subjects, and objects. (C)

$2 . \quad$ I link information in one sentence with information from the previous ones. (MC)

3. I read the whole passage quickly to understand the main idea. (MC)

4. $\quad$ I try to figure out the main idea of each paragraph. (MC)

$5 . \quad$ I continue reading even if I have difficulties. (MC)

6. If I don't understand something such as a word or phrase, I guess its meaning using clues from the text such as a noun, verb, adjective, adverb, surrounding words, verb tense, singular and plural, word elements that is affixes and roots, synonyms, and antonyms. (MC)

$7 . \quad$ I visualize information read. (C)

$8 . \quad$ I re-read for better understanding. (C)

9. $\quad$ I guess the meaning of unknown words. (C)

10. I guess what is coming in the next sentences or paragraphs. (MC)

11. I take notes, highlight or underline the important notes while I am reading the passage. (C)

12. I predict or guess the text meaning. (MC)

13. I confirm predictions. (MC)

14. I interpret the text (make inferences, draw conclusions, etc). (MC)

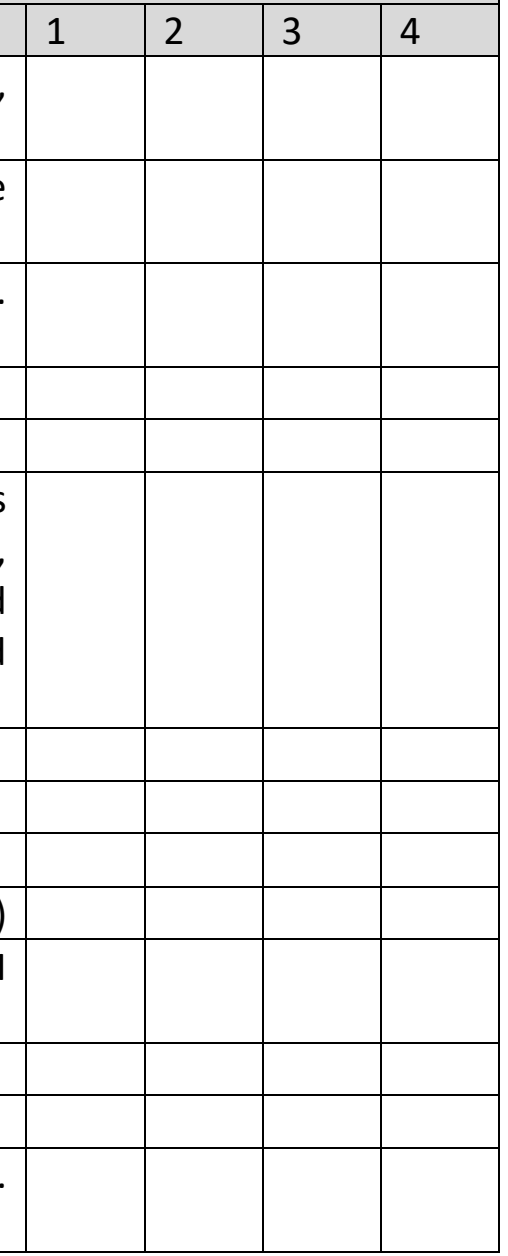




\section{PART D (Post - reading activity)}

Tick $\sqrt{ }$ in the space provided. You are requested to choose only one answer for each of the questions given below.

Each statement is followed by four numbers, 1, 2, 3, and 4, and each number means the following:

1. Strongly Agree

2. Agree

3. Disagree

4. Strongly disagree

- The strategies that I prefer to choose in post-reading activity

\begin{tabular}{|l|l|l|l|l|l|}
\hline No. & Statement & 1 & 2 & 3 & 4 \\
\hline 1. & I make inferences after finishing reading the passage. (C) & & & & \\
\hline 2. & I check or evaluate my comprehension. (C) & & & & \\
\hline 3. & $\begin{array}{l}\text { I go back to read the details of the passage to find the answers } \\
\text { of the questions. (C) }\end{array}$ & & & \\
\hline
\end{tabular}

